\title{
Social perception about birth as a demographic phenomenon
}

\author{
Sandu Mihaela Luminița \\ Ovidius University of Constanta, Romania \\ mihaela naidin@yahoo.com \\ Rus Mihaela \\ Ovidius University of Constanta, Romania \\ Psiholog_m@yahoo.com \\ Pruteanu Lavinia \\ "Petre Andrei" University of Iași, Romania \\ Lavinia_pruteanu@yahoo.com
}

\begin{abstract}
Birth has become a phenomenon of increasing concern. The population of Romania has decreased and is constantly decreasing, the downward evolution is not surprising, all the information on the natural and migratory movement after 1989 define a well-installed demographic decline. Romania's demographic decline is gaining new dimensions and amplifying the deterioration of the country's demographic situation. What is less known and evaluated at the true value is the depth of the deterioration of the age structure of the population in the context of the demographic decline and the implications of this deterioration from the perspective of the possible recovery of the demographic state of the country. The present demographic evolutions, respectively the characteristics of the components that have produced and are still producing these evolutions, foreshadow a strongly negative image regarding the population of Romania in the next decades, if by public policies the birth ratio will not be stimulated.
\end{abstract}

Keywords. birth, phenomenon, demography

\section{The concept of birth}

The birth rate of the population characterizes "the mass of living births within a human community, bounded by characteristics of time and space. The intensity of the population's birth rate shall be determined for the period of the calendar year" (Sora, Mihăescu, 1996, p. 133). The demographic phenomenon of birth is part of the natural movement of the population. Childbirth best expresses the dual character of demographic phenomena.

Natality is the basic phenomenon of population growth, the population increase being the result of the numerical surplus of newborns on deaths, and this social indicator is calculated by reporting the number of live births and the total population of a territory over an interval (eg. per year). Unlike mortality (which refers strictly to a single variable, namely death), we can refer to birth as both the number of newborns and the number of births. The number of live births is not always equal to that of births, because it can be a birth of twins or the product of a birth can be a dead birth. 
More broadly, birth rate is defined as: the frequency or intensity of births in any population (of a country, of a territorial-administrative unit, etc.), being measured on the basis of the ratio of the total number of births (births population, average number).

Fertility is the productivity of that part of the population that is directly involved, with the term being retained for the female population of childbearing age (15-49 years) for marriage promotions.

The most common method of calculating the birth rate is the gross birth rate. The gross birth rate is an indicator of relative intensity measurement and signifies the number of live births per 1,000 inhabitants. The gross birth rate is calculated for a period of time in one year, but can also be determined for periods of time less than one year, months, quarters or semesters. The gross birth rate is an indicator often used in international comparisons. This indicator does not fully reflect the intensity of the birth phenomenon.

The evolution of the population was influenced by the serious decline in birth rate combined with the negative balance of external migration, both leading to an annual population reduction rate of $-0.5 \%$ between 1992 and 2002 .

The main aspects covered by the analysis of the phenomenon of birth are:

- characterization of birth intensity by area (urban and rural) and in territorial aspect;

- differentiated study of birth rates in subcommunities of population, grouped according to various social-economic characteristics, depending on the level of training, by nationalities, etc.;

- characterization of birth rate;

- analysis of living births by rank;

- study of population fertility.

Compared to other demographic phenomena, the birth rate is detached by the difficulties that the explanation of evolution over time, the quantification of the influence of determining factors, raises. At the same time, by its decisive importance on the evolution of the population, the birth rate constitutes the fundamental substrate of demographic policy measures, because the subjective element that can be influenced by such measures is more pronounced than in the case of population mortality.

The analysis of birth rates in sub-collectives, grouped by economic-social, cultural, territorial characteristics, etc., aims to define precisely the influence of these factors on the intensity of the phenomenon.

Studies by some prestigious demographers and specialized bodies highlighted the existing link between income levels and family size. A low level of income favours the existence of families with large numbers of members determined by a high birth rate. As revenue increases, the birth rate is reduced, with the size of the family focusing on a simple reproduction.

After exceeding a certain income threshold so that they no longer condition the standard of living, the birth rate increases causing demographic behaviour oriented towards an enlarged reproduction of the population. Couples freedom to decide on when children appear and their numbers, the economic and social costs raised during the transition period, the problem of housing insurance, social instability and unemployment are among the main causes that have led to the decrease in birthrates.

\section{Influence of fertility on birth rates}


Fertility is that demographic phenomenon that highlights the frequency of the occurrence of the demographic event called birth within the population at risk of this demographic event, i.e. within the female population of childbearing age.

The effort made by countries with high fertility has led the United Nations to reduce the size of the population projected for 2050 from 11.2 billion to 7.7 billion. A particularly important role is the population policy developed by each government according to its size, the resources provided by the ecosystem and the economic potential. In general, it is recommended that these policies encourage families to have few children.

The decline of fertility is a dynamic process influenced by several factors such as increasing training, using contraception, reducing infant mortality and improving economic conditions. (Vișinoiu, 2004, p. 87)

The transition to a low fertility rate involves increasing educational, economic and political opportunities for women. In all societies where they have access to education, women have fewer children due to changes in aspirations and mentalities. The right to vote and the possibility of property or a job gives women the freedom to decide their reproductive destiny. The opportunities created by economic growth diminish the desire to have a large family by replacing it with concern for financial security. In the same sense, nonprofit family planning organizations that have spread around the world work. The studies undertaken by the World Bank show that mainly the improvement of the standard of living leads to the tendency to proliferation of small families.

Family adaptation to the social-cultural environment encompasses a multitude of aspects each of them can significantly influence the demographic behaviour of the family and thus to its birth. The level of education (with specific elements when referring to woman and man) related to membership in a social group can influence in one case the limitation, and in another the stimulation of birth rates.

The prospect of "expenses" required to maintain a child at a certain standard of living of the family may influence the postponement of his birth. From the beginning of capitalism but more frequently and competently in recent decades, interesting studies have been conducted regarding the "cost" of a man and more precisely the maintenance of a child from the moment he is born to the moment he begins to produce. It is understandable that over time, with social progress the "price of maintenance" always increases. This is a reason for which any state cannot deprive itself of the major (economic contribution first) of the family in the growth of the new generation. (Amurag, 1967, p. 62)

Under very restrictive conditions regarding the freedom to decide on the volume of offspring, women in Romania have been able to control their fertility very well, using both the available means of prevention of pregnancy and abortion, practised in even under legality conditions. Birth control was aimed at limiting the number of children and not completely avoiding offspring. Bringing children into the world is considered both a moral duty of spouses and a means of fulfillment and satisfaction for partners.

\section{Factors influencing birth rates}

\section{a. Medical causes.}

Endocrine, gynecological disorders, causes of infertility in both men and women, i.e. the causes of miscarriage are factors that we need to consider and which require diagnosis, preparation of treatment, but also the introduction of prevention measures. In medical practice, registration advances have led to a decrease in medical cases of infertility, but we must point out that there is nevertheless a physiological decrease in fertility as they get older. 


\section{b. Physiological causes}

This group of causes includes the Malthusian implications for the meaning of the child. Another time, in the country, the child was a source of enrichment: he helped work the field, he continued his father's work. "In the city, the child was, to some extent, a hindrance to the freedom of the parents and a source of expenses. It follows that the influence of industrial civilization and urbanization coincides with the reduction in the number of children you want. So, the average final lineage goes from 2.7 children per woman in rural communes to 1.6 children per woman in Paris". (Amurag, 1967)

\section{c. The role of the nuptiality, juvenile consensual unions and divorce}

The number of marriages decreases year-on-year. At the same time, the number of consensual unions, especially juvenile ones, increases. "This decrease in the nuptials is attributed to several factors: modification of relationships between sexes, economic difficulties for young couples, the role of social, fiscal, legal laws, which allow to obtain more advantages in the situation of cohabitation than after marriage. However, the decrease in marriages only significantly influences the birthrate. The number of divorces, however, is increasing without the number of remarried people to increase in the same proportion. The rate of divorce is around 25 per 100 marriages, but the role of divorce does not seem to be decisive in decreasing birthrates" (Amurag, 1967).

\section{d. Influence of the socio-cultural environment.}

The difference in fertility between rural and urban areas can be given by differences in socio-cultural levels. Thus, the study of the level of fertility of couples by the level of instruction of the woman "highlights the following phenomenon: the decline of fertility as the level of training increases is followed by an increase in fertility, the lowest observed in the average category: at the same time, the fertility of women without education significantly exceeds that of women with studies". (Amurag, 1967)

\section{e. Role of the means to limit births}

These means are abortion and contraception. Birth rates are also influenced by a number of factors, the most important of which are:

- the structure of the population by age groups in the sense that the birth rate is higher among the young and less in adult populations and less decreased among the old-age population;

- The traditional structure of the family in monogamous families birth rate is increased while in polygamous families the birth rate is low.

- the standard of living causes a relationship of inverse proportionality: in countries with high birth rates is low and is high in those with a low standard of living;

- the demographic policy of the state is manifested by pronatalist policies that support increased birth rates (Western Europe), denatalist policies aimed at reducing birth rates in states experiencing the phenomenon of demographic explosion (in China or India) and liabilities in which the state does not interfere in any way (the U.S. or China);

- religious influences determine the demographic behavior of the population in terms of birth when they oppose the reduction of birth as is the case in the predominantly Muslim countries of Africa and Asia or Catholic in South America;

- age of marriage can positively influence birth rates when concluded at older ages (Boldureanu, 2004). 

the field:

The declining factors of birth are multiplied and highlighted in part by many analysts in

- relationships between spouses: "matches" between spouses regarding the distribution of family responsibilities, conception of life, appreciation and ranking of values, cultural level, occupational concerns, etc., make up the favorable climate the birth of one or more children sooner or later;

- partner design about the ideal family size or the ideal number of children;

- age of marriage, age of parents at the birth of children, marital status, duration of marriage, number of births, intervals between births. As for the age of the woman at birth, it allows for increased fertility from 15 years to reach a maximum of 20 to 30 years and to decrease to 50 when it becomes null and innuendo. Related to age of marriage, its duration favorably influences the increase in the number of children according to the conditions of demographic behaviour at a time and newborns (Amurag, 1967).

\section{Methodologies} phenomenon.

In this study, social perception of birth rates was pursued as a demographic As specific objectives we have pursued:

- social perception of birth as a demographic phenomenon;

- factors leading to decreased birth rates;

- importance of the phenomenon of birth rate.

Table no.1 Distribution by marital status

\begin{tabular}{|c|c|c|c|}
\hline & $\begin{array}{c}\text { Marital } \\
\text { status }\end{array}$ & Frequency & Percent \\
\hline Valid & Married & 30 & 42,9 \\
\hline & Unmarried & 40 & 57,1 \\
\hline & Total & 70 & 100,0 \\
\hline
\end{tabular}

To carry out this study, the group of subjects was assigned by age groups, depending on the occupational status of the person entered in the sample and by biological type.

Table no. 2 Distribution by gender.

\begin{tabular}{|c|c|c|c|}
\hline & Gender & Frequency & Percent \\
\hline Valid & Female & 40 & 57,1 \\
\hline & Male & 30 & 42,9 \\
\hline & Total & 70 & 100,0 \\
\hline
\end{tabular}

The sample comprises a total of 70 people, the distribution of subjects by sex being relatively equal: 40 female subjects $(57.1 \%)$ and 30 male subjects $(42.9 \%)$.

Table No.3 Distribution by age. 


\begin{tabular}{|c|c|c|c|}
\hline & Age & Frequency & Percent \\
\hline Valid & $20-30$ yrs. & 30 & 42,9 \\
\hline & $35-40$ yrs. & 30 & 42,9 \\
\hline & $45-50$ yrs. & 10 & 14,3 \\
\hline & Total & 70 & 100,0 \\
\hline
\end{tabular}

The group consists of 70 subjects, of whom 30 subjects (42.9\%) between 20 and 30 years of age, 30 subjects (42.9\%) 35 to 40 years of age and 10 subjects $(14.3 \%)$ between 45 and 50 years of age.

This study involved 70 subjects with different social status: 30 subjects are students $(42.9 \%)$, and 40 of subjects $(57.1 \%)$ engineers, teachers, commercial workers, employers, administrative officials).

The sample comprises a total of 70 people, the distribution of subjects by study being as follows: 5 subjects $(7.1 \%)$ with primary education, 15 subjects $(21.4 \%)$ with mean studies and 50 subjects $(71.4 \%)$ with higher education.

\section{Analysis and interpretation of data}

Table no.l Have you heard of the concept of birth?

\begin{tabular}{|c|c|c|c|}
\hline & & Frequency & Percent \\
\hline Valid & Yes & 67 & 95,7 \\
\hline & No & 3 & 4,3 \\
\hline & Total & 70 & 100,0 \\
\hline
\end{tabular}

The majority of those surveyed, namely $95.7 \%$ of them, heard about the concept of birth, while $4.3 \%$ of subjects did not hear about it.

Birth is the basic phenomenon of population growth, the demographic phenomenon of birth is part of the natural movement of the population. (Table No.1)

Table No.2. Do you know what the significance is birth rate in Romania after 1990?

\begin{tabular}{|c|c|c|c|}
\hline & & Frequency & Percent \\
\hline Valid & Grew & 5 & 7,1 \\
\hline & Decreased & 59 & 84,3 \\
\hline & Same & 6 & 8,6 \\
\hline & Total & 70 & 100,0 \\
\hline
\end{tabular}

$84.3 \%$ of those surveyed believe that birth rate in Romania after 1990 decreased significantly, while $8.6 \%$ of subjects believe that the phenomenon of birth in Romania after 1990 remained the same, and $7.1 \%$ believe that birth rate has increased.

Birth is, it was, and it will remain a phenomenon that is more and more concerned. Romania's population has declined and is steadily declining, and the downward evolution is not surprising at all. (tab.2) 
Table No.3 Do you consider that there are significant differences between geographical areas from a demographic point of view?

\begin{tabular}{|c|c|c|c|}
\hline & & Frequency & Percent \\
\hline Valid & Yes & 55 & 78,6 \\
\hline & No & 10 & 14,3 \\
\hline & I don't know & 5 & 7,1 \\
\hline & Total & 70 & 100,0 \\
\hline
\end{tabular}

The majority of those surveyed, namely $78.6 \%$ believe that there are significant differences in demographic terms, whereas $14.3 \%$ of those surveyed do not believe there are significant differences and $7.1 \%$ do not know (table 3 ).

Table No. 4 In which area of the country do you think it is the highest birth rate?

\begin{tabular}{|c|c|c|c|}
\hline & & Frequency & Percent \\
\hline Valid & Moldova & 20 & 28,6 \\
\hline & Transylvania & 25 & 35,7 \\
\hline & Dobrogea & 10 & 14,3 \\
\hline & Banat & 15 & 21,4 \\
\hline & Total & 70 & 100,0 \\
\hline
\end{tabular}

$35.7 \%$ of those surveyed believe that Transylvania has the highest birth rate, while $28.6 \%$ of subjects believe that the highest birth rate is in Moldova, 21.4\% of respondents believe that the highest birth rate is in Banat, and $14.3 \%$ of them believe that the highest birth rate is recorded in Dobrogea region. (TableNo.4)

\begin{tabular}{|} 
Table No.5 How many children do you have? \\
\begin{tabular}{|c|c|c|c|}
\hline & & Frequency & Percent \\
\hline Valid & 1 child & 35 & 50,0 \\
\hline & 2 children & 10 & 14,3 \\
\hline & 3 children & 5 & 7,1 \\
\hline & $\begin{array}{c}\text { More than } 3 \\
\text { children }\end{array}$ & 2 & 2,9 \\
\hline & None & 18 & 25,7 \\
\hline & Total & 70 & 100,0 \\
\hline
\end{tabular}
\end{tabular}

A large proportion of those surveyed, namely $50 \%$ of them have only one child, while only $14.3 \%$ have two children, $7.1 \%$ of subjects have only three children, while $2.9 \%$ of respondents have more than three children, and a fairly high percentage, namely $25.7 \%$ have no children. (Table No 5) 
Table No.6 Which you consider to be the number of children in a family in Romania?

\begin{tabular}{|c|c|c|c|}
\hline & & Frequency & Percent \\
\hline Valid & 1 child & 50 & 71,4 \\
\hline & 2 children & 15 & 21,4 \\
\hline & $\begin{array}{c}\text { More than } 3 \\
\text { children }\end{array}$ & 5 & 7,1 \\
\hline & Total & 70 & 100,0 \\
\hline
\end{tabular}

The vast majority of those surveyed, namely $71.4 \%$ consider that the optimal number of children in a family in Romania is one child, while $21.4 \%$ of those surveyed believe that the optimal number is two children, and a fairly small percentage, namely $7.1 \%$ of those surveyed, believe that more than three children is the optimal number in a family in Romania. (table no.6)

Table No.7 When you think a family should be to make the decision to have a child?

\begin{tabular}{|c|c|c|c|}
\hline & & Frequency & Percent \\
\hline Valid & Right after marriage & 10 & 14,3 \\
\hline & $\begin{array}{c}\text { After two years of } \\
\text { marriage }\end{array}$ & 44 & 62,9 \\
\hline & Not planned & 12 & 17,1 \\
\hline & I don't know & 4 & 5,7 \\
\hline & Total & 70 & 100,0 \\
\hline
\end{tabular}

$62.9 \%$ of those surveyed believe that a family should make the decision to have a child two years after marriage, while $17.1 \%$ believe that this is not planned, $14.3 \%$ of those surveyed believe that immediately after marriage a family must make the decision to have a child, and $5.7 \%$ did not know what to answer. (table no.7)

Table No.8 Do you agree to the "the child can come at any time, even if there is no family"?

\begin{tabular}{|c|c|c|c|}
\hline & & Frequency & Percent \\
\hline Invalid & Yes & 15 & 21,4 \\
\hline & No & 55 & 78,6 \\
\hline & Total & 70 & 100,0 \\
\hline
\end{tabular}

The majority, namely, $78.6 \%$ of those surveyed do not agree with the phrase "the child can come at any time, even if there is no family", while $21.4 \%$ agree with this phrase. (Table No. 8)

Table No.9 Do you consider that the occurrence of a child is increasing social responsibility?

\begin{tabular}{|c|c|c|c|}
\hline & & Frequency & Percent \\
\hline Invalid & Yes & 60 & 85,7 \\
\hline & No & 6 & 8,6 \\
\hline & $\begin{array}{c}\text { I don't } \\
\text { know }\end{array}$ & 4 & 5,7 \\
\hline & Total & 70 & 100,0 \\
\hline
\end{tabular}


$85.7 \%$ of study participants believe that the appearance of a child in the family increases social responsibility, while $8.6 \%$ of those surveyed do not agree with this, and $5.7 \%$ do not know. (Table No 9)

Table No.10 Do you consider that birth rate as a phenomenon can affect the population of a country?

\begin{tabular}{|c|c|c|c|}
\hline & & Frequency & Percent \\
\hline Valid & Very much & 35 & 50,0 \\
\hline & Much & 15 & 21,4 \\
\hline & Very little & 10 & 14,3 \\
\hline & Little & 7 & 10,0 \\
\hline & I don't know & 3 & 4,3 \\
\hline & Total & 70 & 100,0 \\
\hline
\end{tabular}

A large proportion of those surveyed, namely $50 \%$ believe that birth rate as a demographic phenomenon can greatly affect a country's population, while $21.4 \%$ believe that birth can affect much a country's population, $14.3 \%$ believe this phenomenon can affect very little the population of a country, $10 \%$ of subjects believe that birth rates affect a country's population slightly, and $4.3 \%$ do not know. (Table No.10)

Table No.11 If a woman cannot have children, can she use modern fertilization methods?

\begin{tabular}{|c|c|c|c|}
\hline & & Frequency & Percent \\
\hline Invalid & Yes & 40 & 57,1 \\
\hline & No & 25 & 35,7 \\
\hline & I don't know & 5 & 7,1 \\
\hline & Total & 70 & 100,0 \\
\hline
\end{tabular}

$57.1 \%$ of those who participated in the study believe that if a woman cannot have children naturally she can use modern fertilization methods, while $35.7 \%$ do not agree and $7.1 \%$ do not know. (Table.11)

Table No.12 Women's empowerment and participation increasing its growth in economic activities in out of the household is a factor in lowering birth rates?

\begin{tabular}{|c|c|c|c|}
\hline & & Frequency & Percent \\
\hline Valid & Yes & 45 & 64,3 \\
\hline & No & 22 & 31,4 \\
\hline & I don't know & 3 & 4,3 \\
\hline & Total & 70 & 100,0 \\
\hline
\end{tabular}

Most of those surveyed, namely $64.3 \%$ believe that women's empowerment and her increasing participation in economic activities outside the household is a factor that leads to a decrease in birth rate, while $31.4 \%$ disagree with this, and $4.3 \%$ do not know.

Table no. 13 Do you think that the degradation of the standard of living and unemployment leads to a decrease in birth rate? 


\begin{tabular}{|c|c|c|c|}
\hline & & Frequency & Percent \\
\hline Valid & Yes & 48 & 68,6 \\
\hline & No & 16 & 22,9 \\
\hline & I don't know & 6 & 8,6 \\
\hline & Total & 70 & 100,0 \\
\hline
\end{tabular}

$68.6 \%$ of those surveyed believe that the degradation of living standards and unemployment leads to a decrease in birth rate, while $22.9 \%$ of those surveyed do not agree and 8.6\% did not know. (Table No 13)

Table No.14 Increasing social mobility leads to a lower birth rates?

\begin{tabular}{|c|c|c|c|}
\hline & & Frequency & Percent \\
\hline Valid & Very much & 36 & 51,4 \\
\hline & Much & 12 & 17,1 \\
\hline & Very little & 10 & 14,3 \\
\hline & Little & 5 & 7,1 \\
\hline & Not at all & 3 & 4,3 \\
\hline & I don't know & 4 & 5,7 \\
\hline & Total & 70 & 100,0 \\
\hline
\end{tabular}

A large proportion of those who participated in the study, namely $51.4 \%$ believe that increasing social mobility leads a lot to lower birth rates, while $17.1 \%$ believe that social mobility affects birth rates a lot, others, i.e. $14.3 \%$ believe it affects very little birth rate, $7.1 \%$ believe that only a little is impaired, $4.3 \%$ believe it does not affect at all, and $5.7 \%$ do not know. (Table No 14)

Table No.15 Economic and social context influence birth rates?

\begin{tabular}{|c|c|c|c|}
\hline & & Frequency & Percent \\
\hline Valid & Very much & 38 & 54,3 \\
\hline & Much & 10 & 14,3 \\
\hline & Very little & 8 & 11,4 \\
\hline & Little & 7 & 10,0 \\
\hline & Not at all & 4 & 5,7 \\
\hline & I don't know & 3 & 4,3 \\
\hline & Total & 70 & 100,0 \\
\hline
\end{tabular}

The majority of those surveyed, namely $54.3 \%$ believe that birth rates are greatly influenced by the economic and social context, while $14.3 \%$ say it is much influenced, $11.4 \%$ believe that very little is influenced by birth, $10.0 \%$ consider that birth rate is little influenced, $5.7 \%$ believe that birth is not at all influenced by the economic and social context, and $4.3 \%$ do not know. (Table No 15)

Table No.16 Do you consider that the birth rate is decrease because more and more young people decide to live in consensual cohabitation? 


\begin{tabular}{|c|c|c|c|}
\hline & & Frequency & Percent \\
\hline Valid & Yes & 40 & 57,1 \\
\hline & No & 23 & 32,9 \\
\hline & I don't know & 7 & 10,0 \\
\hline & Total & 70 & 100,0 \\
\hline
\end{tabular}

Most of them, namely $57.1 \%$ believe that birth rates are declining because more and more young people decide to live in consensual cohabitation, whereas $32.9 \%$ disagree with this, and $10.0 \%$ do not know. (Table No 16)

Table No. 17 Freedom of abortion leads to decreased birth rate?

\begin{tabular}{|c|c|c|c|}
\hline & & Frequency & Percent \\
\hline Valid & Yes & 38 & 54,3 \\
\hline & No & 22 & 31,4 \\
\hline & I don't know & 10 & 14,3 \\
\hline & Total & 70 & 100,0 \\
\hline
\end{tabular}

The majority of those surveyed, namely $54.3 \%$ believe that freedom of abortion leads to a decrease in birth rate, while $31.4 \%$ do not believe that if abortion is no longer banned it leads to a decrease in birth rate and $14.3 \%$ did not know what to answer. (Table No.17)

Table No.18 Advanced age at which women decide to have a child lead to a decrease in birth rate?

\begin{tabular}{|c|c|c|c|}
\hline & & Frequency & Percent \\
\hline Valid & Very much & 20 & 28,6 \\
\hline & Much & 10 & 14,3 \\
\hline & Very little & 12 & 17,1 \\
\hline & Little & 15 & 21,4 \\
\hline & Not at all & 10 & 14,3 \\
\hline & I don't know & 3 & 4,3 \\
\hline & Total & 70 & 100,0 \\
\hline
\end{tabular}

The vast majority of those who participated in the study, namely $28.6 \%$ believe that age greatly affects birth rates, $14.3 \%$ believe that birth rates are affected much by women's age, $17.1 \%$ believe this affects very little birth rate, $21.4 \%$ think age affects little birth rate, $14.3 \%$ believe it does not affect at all, and $4.3 \%$ do not know. (Table No.18)

Table No.19 Consider that the weakening of cultural norms and religious ones influence birth rates?

\begin{tabular}{|c|c|c|c|}
\hline & & Frequency & Percent \\
\hline Valid & Yes & 23 & 32,9 \\
\hline & No & 36 & 51,4 \\
\hline & I don't know & 11 & 15,7 \\
\hline & Total & 70 & 100,0 \\
\hline
\end{tabular}


$51.4 \%$ of subjects do not consider that weakening cultural and religious norms influence birth, while $32.9 \%$ of those surveyed agree that birth rates are influenced by the weakening of cultural and religious norms, and $15.7 \%$ did not know what to answer. (Table No.19).

Table No.20 Do you consider that it should be designed and implemented certain economic rules to support the family?

\begin{tabular}{|c|c|c|c|}
\hline & & Frequency & Percent \\
\hline Valid & Yes & 52 & 74,3 \\
\hline & No & 12 & 17,1 \\
\hline & I don't know & 6 & 8,6 \\
\hline & Total & 70 & 100,0 \\
\hline
\end{tabular}

A large proportion of those who participated in the study, namely $74.3 \%$ believe that certain economic rules should be designed and implemented to support the family, while $17.1 \%$ of subjects do not believe that certain rules should be designed and 8.6\% do not know. (Table No 20)

\section{Conclusions}

From the study we conducted on the social perception of birth as a demographic phenomenon, we found that birth rates became a very important phenomenon, which must be seriously considered. Certain economic norms must be designed and implemented to support family and child.

The number of marriages decreases year-on-year due to the fact that more and more young people prefer to live in consensual cohabitation. Most people prefer to have a child because children are not a game, raising them requires certain sacrifices, and last but not least certain costs, and many make plans to bring them into the world. If the children used to be a happy occurrence, now it's become a calculation. Surely children complete life and are the most delicate and beautiful beings. Bringing children into the world is considered both a moral duty of spouses and a means of fulfillment and satisfaction for partners.

Nowadays the woman is much more emancipated, participating in numerous activities outside the household, puts her career first, leaving the family in the last place and although she marries does not mean that she decides to have children. In all societies where they have access to education, women have fewer children due to changes in aspirations and mentalities.

Those who marry decide to have children after two years of marriage, because the opportunities created by economic growth diminish the desire to have children's concern for financial security being much greater than having children.

More and more women are resorting to modern fertilization methods if they can't have children naturally. Women today know how to control their fertility very well, using both the means of prevention of pregnancy and abortion, and the fact that there are contraception, freedom of abortion, all of which only leads to decreased birth.

Growing social mobility is a very important factor leading to lower birth rates, as more and more young people decide to leave the country for a better future.

Other factors leading to decreased birth rates are: age of marriage, age of parents at the birth of children, duration of marriage, conception of life, appreciation and ranking of values, influence of cultural and religious norms. 


\section{References}

[1] * Journal of „Romanian Sociology”, edited by the Romanian Sociology Association, University of Bucharest, Faculty of Sociology and Social Assistance in collaboration with Polirom Publishing House, Vol.II, Nr.3, 2005, Director Septimiu Chelcea;

[2] A.R. Stăiculescu, D. Jitcov, Sociology, Constanţa, Ovidius Publishing House, University Press, 2002;

[3] ] Statistical Yearbook of Romania 2004, National Institute of Statistics, Bucharest, 2005;

[4] Boldureanu Daniel, Demographic behavior of the population, Iaşi, Performantică Publishing House, 2004;

[5] Ionaşcu Costel, Morbidity, mortality and environmental quality, University Publishing House, Craiova, 2003;

[6] Pescaru Alexandru, Population and Birth in the World, Bucharest, Scientific Publishing House, 1967;

[7] Rus Mihaela, Seceleanu Andra, Society and Communication, "Andrei Şaguna" Foundation Publishing House, Constanta, 2005;

[8] Mihaela Rus, Tanase Tasente, Ciprian Vasile Rus, Preventive behaviors and attitudes of the children as active participants in road traffic, Acta Universitatis Danubius. Administratio 11(1) 2019.

[9] V. Sora, I. Hristache, C. Mihăescu, Demography and social statistics, Bucharest, Economic Publishing House, 1996;

[10] Vişinoiu Niculae, Population of the globe, Bucharest, Synthetic edition of economic studies, 2004; 